\title{
Viscosity and volume properties of the Al-Cu melts
}

\author{
N. Konstantinova, A. Kurochkin, and P. Popel \\ Institute of Physics and Technology, Ural State Pedagogical University, 26 Cosmonavtov ave., Ekaterinburg, 620017, \\ Russia, e-mail: pspopel@mail.ru
}

\begin{abstract}
Temperature dependences of the kinematic viscosity $v$ and the density $\rho$ of Al-Cu melts were investigated in the same regime taking into account that viscometric experiments with the melts enriched with cupper have not been repeated since $1960^{\text {th }}$ and densimetric measurements did not perform before at all. The first measurements were fulfilled using the method of dumping oscillation of a crucible filled in by a melt investigated. Its precision was as high as $1.5 \%$. Density was measured using the gamma-absorption method with the accuracy of 0.2 to $0.3 \%$. Crucibles of $\mathrm{BeO}$ were used in both the cases. In the course of the measurements a distinct branching of the heating and cooling curves were fixed below some temperature characteristic of each composition for most of the investigated samples. The branching temperature systematically changes with growth of cupper content. The authors believe that the effect is caused by the irreversible transition of the melts from microheterogeneous state inherited from the initial rough materials into a true solution state.
\end{abstract}

\section{Introduction}

Copper-aluminum (aluminum bronzes) and aluminumcopper (duralumins) alloys find extensive applications in various fields of engineering. Their physical properties (electrical and thermal conductivity, mechanical properties, corrosion resistance, and so on) are largely defined by the correlation of concentrations of basic components. However, these characteristics are significantly affected by the production technology as well, in particular, by the temperature conditions of melting and casting. It is known that many of aluminum alloys for a long time after the melting of components are capable of existing in nonequilibrium or metastable microheterogeneous states, the destruction of which requires overheating above liquidus to temperatures typical of each system or some other energy stimulation [1]. As a result of this stimulation, the melt irreversibly goes to the thermodynamically stable state of homogeneous solution, which is retained under subsequent cooling down to liquidus temperature: the process of irreversible homogenization of melt occurs. Experiments reveal that the homogenization of melt causes a significant variation of the kinetics of its crystallization, and this in turn leads to the modification of the structure of ingot or casting being formed. The temperature of overheating required for destroying the microheterogeneous state may be determined by the position of the branch point of temperature dependences of some property of the melt, obtained in the process of heating after the melting of components and subsequent cooling [2]. The kinematic viscosity $\nu$ and the density $\rho$ are among the properties.

Previous measurements of kinematic viscosity of copper-aluminum alloys were performed only in concentration intervals of approximately up to 20 at.\% of one of the components. The least studied are the copper-based alloys. In the only study known to us, Chursin [3] obtained values of kinematic viscosity of alloys with aluminum content of 5, 9, 13, 17, 21, 24, and 28 at.\% for only two temperatures, namely, 1100 and $1200^{\circ} \mathrm{C}$.

The viscosity of $\mathrm{Cu}-\mathrm{Al}$ alloys rich in aluminum is studied in more detail. Nevertheless, referred to as the most reliable data on temperature dependences of the viscosity of copper-aluminum melts in the relatively recent review of Ganesan et al. [4] are still the half-acentury-old results of Gebhardt et al. [5] and of Korol'kov [6]; as to the concentration dependence, it is just noted that the viscosity of liquid aluminum increases as a result of addition of copper. None of the studies mentioned above involved measurements in the modes of heating and subsequent cooling of the sample; therefore, no reference is made to possible structure transformations of alloys.

The most accurate measurements were apparently performed by Zamyatin et al. [7], who measured the $v(t)$ dependences in the temperature interval between liquidus and $1100^{\circ} \mathrm{C}$ for alloys with a copper content of up to 22 at.\% and did this exactly in the modes of 
heating and subsequent cooling. They revealed very non trivial features on the $v(t)$ curves, indicative of the possibility of reversible or irreversible (depending on the copper content) structure transformations in the investigated melts. However, we are not aware of previous systematic viscosimetric investigations of copper-aluminum alloys in the entire range of compositions from zero to $100 \%$.

We know no works dedicated to the density measurements for the $\mathrm{Cu}-\mathrm{Al}$ melts.

That is why in the present study, we measured the temperature dependences of kinematic viscosity of $\mathrm{Cu}$ Al melts containing from zero to $100 \%$ of the second component and the temperature dependences of density for some $\mathrm{Al}-\mathrm{Cu}$ melts in the mode of heating and subsequent cooling of samples between liquidus and $t=1150-1450^{\circ} \mathrm{C}$.

\section{Measurement procedures}

\subsection{Viscosity measurements}

The kinematic viscosity was measured using a method based on registering the period and decrement of damping of torsional vibrations of cylindrical crucible with liquid under investigation. The values of kinematic viscosity were calculated by the formula derived by Shvidkovskii [8] as a result of solution of the inner hydrodynamic problem for low-viscous liquids such as most of liquid metals:

$v=\frac{1}{\pi}\left(\frac{K}{M R}\right)^{2} \frac{\left[\delta-\left(\delta_{0} / \tau_{0}\right) \tau\right]^{2}}{\tau \sigma^{2}}$.

Here, $M$ and $R$ denote the mass of melt and the crucible radius, respectively; $K$ is the moment of inertia of the suspension system; $\delta$ and $\tau$ denote the decrement of damping and the period of vibrations of the system with melt, respectively; $\delta_{0}$ and $\tau_{0}$ - the same for an empty system; and $\sigma$ is a quantity which takes into account the transmission of momentum from the crucible bottom, the values of which were determined by the method of successive approximations.

The measurements were performed in a setup, the schematic diagram of which is given in [1]. For raising the sensitivity of the viscosimeter, the parameters of its suspension system were optimized, namely, beryllium oxide crucibles of inside radius of $8.5 \mathrm{~mm}$ were employed, the mass of sample ranged from 30 to $60 \mathrm{~g}$, the moment of inertia of the suspension system was $8.58 \cdot 10^{-4} \mathrm{~kg} \mathrm{~m}^{2}$, the diameter of Nichrome filament was $0.24 \mathrm{~mm}$, and the period of vibrations was about $3.5 \mathrm{~s}$. The foregoing physical and geometric parameters of the suspension system provided for the feasibility of the conditions within which formula (1) was derived,

$H \geq 1.85 R$,

$y=\frac{2 \pi R^{2}}{\tau \nu} \geq 100$, where $H$ is the height of sample.

The viscosity is determined in a process of indirect measurements and calculated as a function of a number of directly measured quantities. Svidkovskii's equation (1) sets a complex dependence of kinematic viscosity on various parameters determined experimentally. The maximal contribution to the error of measurement of kinematic viscosity is made by the error of determination of decrement of damping of vibrations. For raising the accuracy of its determination, we used an ingenious system of registering the amplitude. The oscillation of light beam reflected from the mirror of the suspension system onto a transparent rule was registered by a video camera. Then, following the computer processing of the video image, the least squares method was used for approximating by linear function the oscillation number dependence of amplitude logarithm. The decrement is proportional to the angular coefficient of this function. The error of its determination was calculated by the standard formula of the least squares method. This error is between 1 and $2 \%$ for different samples and temperatures.

Therefore, the overall relative error of determination of kinematic viscosity at $p=0.95$ does not exceed $2.5 \%$.

The random component of error alone is of importance from the standpoint of analyzing the reliability of various anomalies on the temperature dependences of viscosity. In our case, it is very close to the error of determination of the decrement of damping of vibrations, i.e., it does not exceed $2 \%$ at $p=0.95$.

\subsection{Density measurements}

Densitometric measurements using penetrating $\gamma$ radiation are based on the well-known formula of $\gamma$ quanta flux attenuation by a sample of $\rho$ density:

$I=I_{\mathrm{o}} B \exp (-\mu \rho l)$

where $I_{0}, I$ are the beam intensities before and after the absorber (the sample) respectively; $l$ is the $\gamma$-quanta path length in the sample; $\mu$ is the mass attenuation factor that depends on the chemical composition of the sample and the $\gamma$-quanta energy; $B$ is the build-up factor that takes into account the amount of $\gamma$-quanta remaining in the beam of finite width after interacting with the atoms of the absorber.

The block diagram of the gamma densitometer is given in figure 1 .

The isotope ${ }^{137} \mathrm{Cs}$ of initial activity $1 \mathrm{Ci}$ is the source of gamma-radiation- 1 in it. The intensity of the $\gamma$-quanta beam passing through the diameter of the cylinder beryllium oxide crucible with the sample- 2 is measured by a scintillation detector-3 with a NaJTe monocrystal. The pulses from the detector come to the input of the radiometer-4 which performs their formation, amplitude discrimination and counting with the subsequent transfer of the information onto a digital printer-5. The temperature of the sample is determined by one of the tungsten-rhenium thermocouples-6, which is immersed into the sample in a protective cover in close proximity to the radiographed zone. The thermal electromotive 
force of the thermocouple is measured by a digital voltmeter-7 which is also connected to the digital printer.

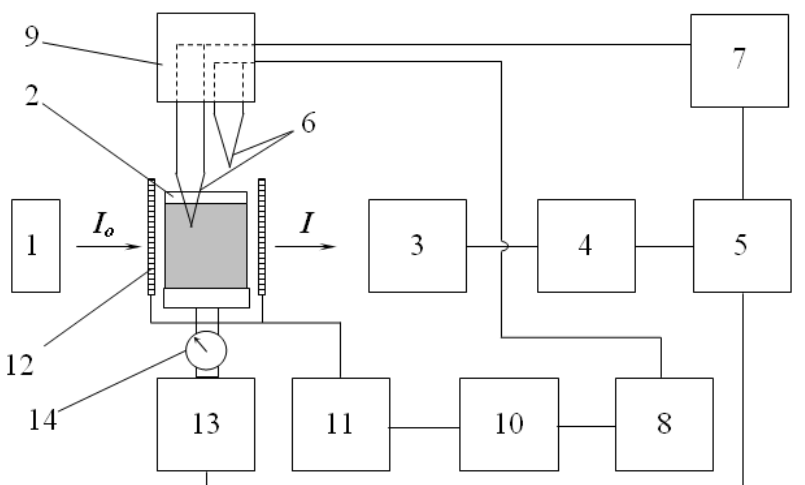

Fig. 1. Block diagram of gamma densitometer: 1-the source of $\gamma$-quanta; 2-crucible with the sample; 3-scintillation detector; 4-radiometer; 5-printer; 6-thermocouples; 7voltmeter; 8-thermoregulator; 9-thermostat; 10-thyristor unit; 11-power transformer; 12-tantalum heater; 13-device for controlled vertical movement of the crucible; 14 -indicator micrometer.

The second thermocouple- 6 is above the sample. This is a feedback sensor which is used to select the temperature regimes of the assembly operation. These regimes are controlled by a precision program temperature regulator- 8 . The cold ends of both thermocouples are in the thermostat-9. The temperature regulator controls the voltage on the transformer-10 through the thyristor power unit-10, allowing heating the sample continuously or discretely by means of the tantalum heater-12.

The statistical error of measuring the intensity of gamma-quanta flux passing through the crucible with melt is less then $0.2 \%$.

\section{Experimental results}

\subsection{Results of the viscometric experiments}

The temperature dependences of kinematic viscosity, obtained in the process of heating and subsequent cooling of samples, are given in figures 2 and 3.

In their analysis, attention is first of all drawn to the discrepancy between the $v(t)$ curves corresponding to the modes of heating and cooling (viscosity hysteresis) for all samples, except for liquid copper and $\mathrm{Cu}_{3} \mathrm{Al}$ alloy of stoichiometric composition. The discrepancy between them is very clearly pronounced for some compositions and less clearly for others; however, in all of the identified cases it significantly exceeds the error of measurements. The position of the branch point gradually shifts from $1300^{\circ} \mathrm{C}$ to $950-980^{\circ} \mathrm{C}$ with increasing concentration of aluminum. In the majority of cases, the heating curve has a rather complex shape, while the cooling curve is close to a simple exponent described by the Arrhenius equation. For liquid aluminum and alloys containing 90 and 82.9 at.\% aluminum, the viscosity hysteresis has a peculiar form first noted by Zamyatin et al. [7, 9]. In this case, quite an abrupt decrease in viscosity is observed on the heating curve in the vicinity of $950^{\circ} \mathrm{C}$; however, under subsequent cooling after branching at the same temperature the 1 divergence of polytherms is observed only up to $700^{\circ} \mathrm{C}$. After that, the viscosity abruptly increases to initial values and, in what follows, the cooling curve coincides with the initial segment of the heating curve (close hysteresis).

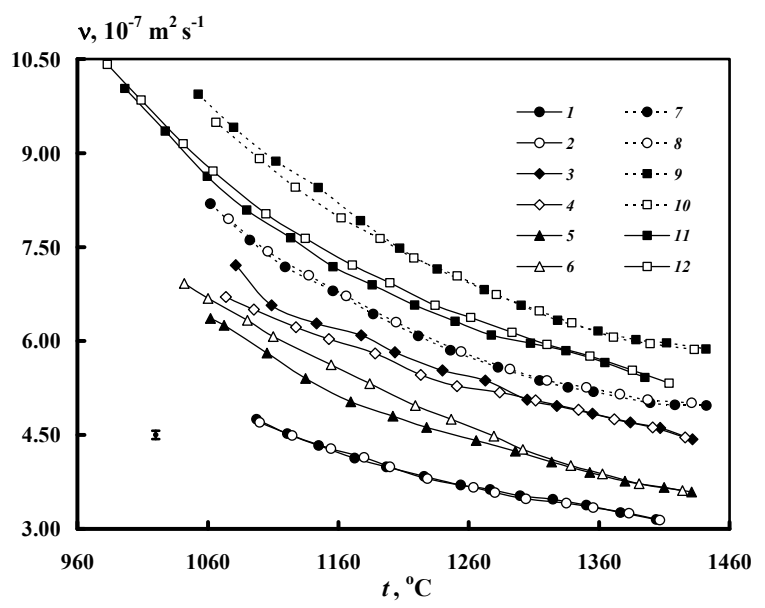

Fig. 2. The temperature dependence of kinematic viscosity of copper-rich melts of $\mathrm{Cu}-\mathrm{Al}$ system: (1) 100 at.\% $\mathrm{Cu}$, (2) 100 ,

(3) 90 (for convenience of the reader, the curve is shifted upward by $0.5 \times 10^{-7} \mathrm{~m}^{2} \mathrm{~s}^{-1}$ ), (4) 90 (shifted by $\left.0.5 \times 10^{-7}\right)$, (5) 82

(0), (6) $82(0),(7) 75\left(0.8 \times 10^{-7}\right)$, (8) $75\left(0.8 \times 10^{-7}\right)$, , (9) 70

$\left(1.8 \times 10^{-7}\right),(10) 70\left(1.8 \times 10^{-7}\right),(11) 60\left(1.3 \times 10^{-7}\right),(12) 60$

$\left(1.3 \times 10^{-7}\right)$. Odd designations - heating, even designations cooling.

$v, 10^{-7} \mathrm{~m}^{2} \mathrm{~s}^{-1}$

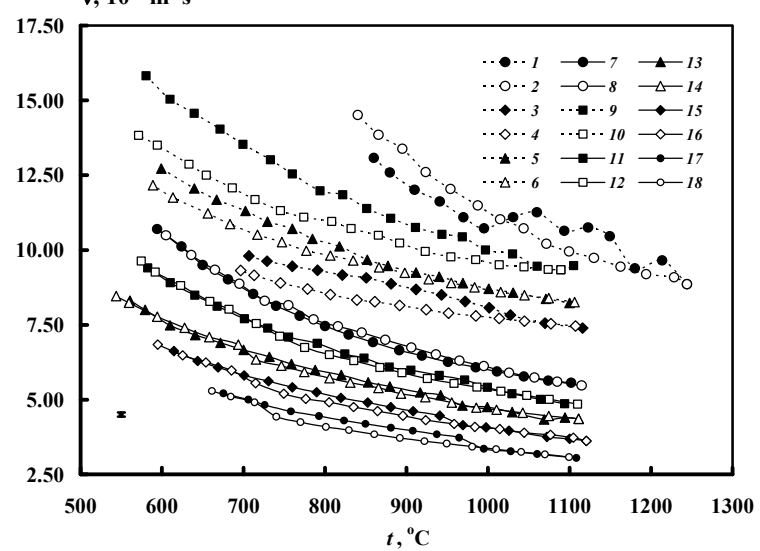

Fig. 3. The temperature dependence of kinematic viscosity of aluminum-rich melts of $\mathrm{Cu}-\mathrm{Al}$ system: (1) 50 at.\% $\mathrm{Al}$ (for convenience of the reader, the curve is shifted upward by $\left.3.7 \times 10^{-7} \mathrm{~m}^{2} \mathrm{~s}^{-1}\right),(2) 50$ (shifted by $\left.3.7 \times 10^{-7}\right),(3) 60\left(3.0 \times 10^{-7}\right)$, (4) $60\left(3.0 \times 10^{-7}\right),(5) 67.8\left(4.2 \times 10^{-7}\right),(6) 67.8\left(4.2 \times 10^{-7}\right),(7)$ $73\left(1.8 \times 10^{-7}\right),(8) 73\left(1.8 \times 10^{-7}\right),(9) 75\left(3.5 \times 10^{-7}\right),(10) 75$ $\left(3.5 \times 10^{-7}\right),(11) 78\left(1.5 \times 10^{-7}\right),(12) 78\left(1.5 \times 10^{-7}\right),(13) 82.9$ $\left(0.8 \times 10^{-7}\right),(14) 82.9\left(0.8 \times 10^{-7}\right),(15) 90\left(0.5 \times 10^{-7}\right),(16) 90$ $\left(0.5 \times 10^{-7}\right),(17) 100(0),(18) 100(0)$. Odd designations heating, even designations - cooling.

Assuming that the values obtained under cooling correspond to thermodynamically stable equilibrium state of the melt, quadratic interpolation was employed for calculating the values of kinematic viscosity of investigated samples at fixed temperatures (see Table 1) 
and for constructing the isotherms of viscosity of the $\mathrm{Cu}-\mathrm{Al}$ system, which are given in figure 4 . Note the gently sloping maximum of $v$ in the vicinity of the composition of $\mathrm{Cu}-30$ at.\% $\mathrm{Al}$ and a sharper maximum in the vicinity of stoichiometric composition of $\mathrm{CuAl}_{3}$. The authors of $[10,11]$ observed a maximum on viscosity isotherms for a composition corresponding to $\mathrm{Cu}_{3} \mathrm{Al}$. It was for the first time that we observed an extremum with the composition of $\mathrm{CuAl}_{3}$.

Table 1. The kinematic viscosity of $\mathrm{Cu}-\mathrm{Al}$ melts at fixed values of temperature, $10^{-7} \mathrm{~m}^{2} \mathrm{~s}^{-1}$.

\begin{tabular}{|c|c|c|c|}
\hline$x_{\mathrm{Al}}$, at. $\%$ & $600^{\circ} \mathrm{C}$ & $700^{\circ} \mathrm{C}$ & $800^{\circ} \mathrm{C}$ \\
\hline 0 & - & - & - \\
\hline 10 & - & - & - \\
\hline 18 & - & - & - \\
\hline 25 & - & - & - \\
\hline 30 & - & - & - \\
\hline 40 & - & - & - \\
\hline 50 & - & - & - \\
\hline 60 & - & 6.24 & 5.59 \\
\hline 67.8 & 7.70 & 6.58 & 5.67 \\
\hline 73 & 8.71 & 7.12 & 5.85 \\
\hline 75 & 9.83 & 8.48 & 7.41 \\
\hline 78 & 7.64 & 6.25 & 5.14 \\
\hline 82.9 & 6.90 & 6.00 & 4.96 \\
\hline 90 & 6.27 & 5.38 & 4.45 \\
\hline 100 & - & 4.99 & 4.11 \\
\hline$x_{\mathrm{Al}}$, at. $\%$ & $900^{\circ} \mathrm{C}$ & $1000^{\circ} \mathrm{C}$ & $1100^{\circ} \mathrm{C}$ \\
\hline 0 & - & - & 4.68 \\
\hline 10 & - & - & 5.96 \\
\hline 18 & - & - & 6.21 \\
\hline 25 & - & - & 6.76 \\
\hline 30 & - & - & 7.10 \\
\hline 40 & - & 8.66 & 6.92 \\
\hline 50 & 9.45 & 7.60 & 6.27 \\
\hline 60 & 5.09 & 4.73 & 4.51 \\
\hline 67.8 & 4.95 & 4.45 & 4.14 \\
\hline 73 & 4.87 & 4.20 & 3.84 \\
\hline 75 & 6.61 & 6.09 & 5.84 \\
\hline 78 & 4.31 & 3.77 & 3.51 \\
\hline 82.9 & 4.37 & 3.91 & 3.58 \\
\hline 90 & 3.94 & 3.53 & 3.23 \\
\hline 100 & 3.70 & 3.36 & 3.10 \\
\hline$x_{\mathrm{Al}}$, at. $\%$ & $1200^{\circ} \mathrm{C}$ & $1300^{\circ} \mathrm{C}$ & $1400^{\circ} \mathrm{C}$ \\
\hline 0 & 4.00 & 3.50 & 3.20 \\
\hline 10 & 5.19 & 4.57 & 4.11 \\
\hline 18 & 5.15 & 4.31 & 3.68 \\
\hline 25 & 5.54 & 4.70 & 4.27 \\
\hline 30 & 5.74 & 4.76 & 4.17 \\
\hline 40 & 5.60 & 4.70 & 4.21 \\
\hline 50 & 5.45 & - & - \\
\hline 60 & - & - & - \\
\hline 67.8 & - & - & - \\
\hline 73 & - & - & - \\
\hline 75 & - & - & - \\
\hline 78 & - & - & - \\
\hline 82.9 & - & - & - \\
\hline 90 & - & - & - \\
\hline 100 & - & - & - \\
\hline
\end{tabular}

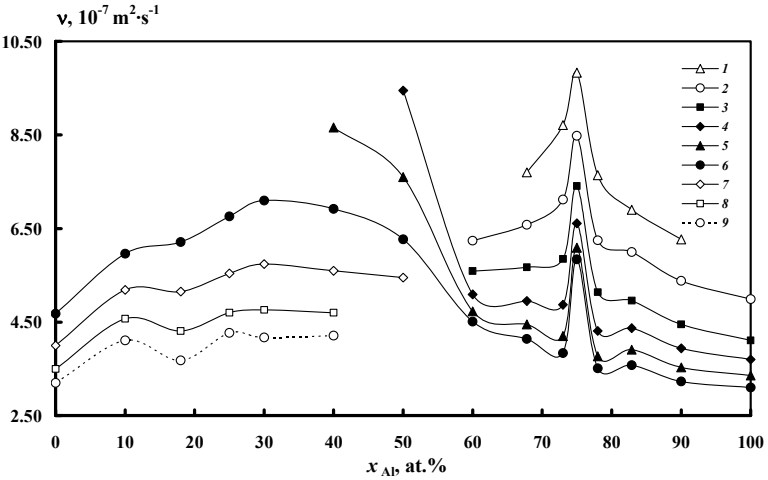

Fig. 4. The isotherms of kinematic viscosity of melts of $\mathrm{Cu}-\mathrm{Al}$ system: (1) $600^{\circ} \mathrm{C}$, (2) 700, (3) 800 , (4) 900 , (J) 1000 , (6) $1100,(7) 1200,(8) 1300,(9) 1400$.

The temperature dependences of viscosity obtained under cooling were approximated, in accordance with the Arrhenius equation, by the exponential dependence

$v=v_{0} \cdot \exp \left(\frac{E}{R T}\right)$

where $v_{0}$ is the constant of the substance under investigation, $E$ is the activation energy of viscous flow, $R$ is the universal gas constant, and $T$ is the thermodynamic temperature. Table 2 gives the parameters of these approximations, and figure 5 - the concentration dependence of the activation energy of viscous flow. Given for samples containing 82.9, 90 and 100 at. $\% \mathrm{Al}$ are the values of $E$ which correspond to the high-temperature segment of the cooling curve.

Along with the extrema in the vicinity of the same compositions of $\mathrm{CuAl}_{3}$ and $\mathrm{Cu}-30$ at.\% $\mathrm{Al}$, note the general tendency for an increase in activation energy by a factor of two-three in the case of transition from aluminum-based alloys to copper-enriched alloys.

Table 2. The values of activation energy $E$ of viscous flow, the errors of its approximation $\Delta_{E}$ and of constant $v_{0}$ in formula (3) for $\mathrm{Cu}-\mathrm{Al}$ melts with different contents of aluminum.

\begin{tabular}{|c|c|c|c|}
\hline \multirow{2}{*}{$x_{\mathrm{Al}}$, at. $\%$} & $E$ & $\Delta_{E}$ & \multirow{2}{*}{$v_{0}, 10^{-7} \mathrm{~m}^{2} \mathrm{~s}^{-1}$} \\
\cline { 2 - 3 } & \multicolumn{2}{|c|}{$\mathrm{J} \mathrm{mol}^{-1}$} & \\
\hline 0 & 24600 & 500 & 0.54 \\
10 & 23600 & 400 & 0.75 \\
18 & 32600 & 400 & 0.35 \\
25 & 29400 & 1000 & 0.51 \\
30 & 34000 & 600 & 0.36 \\
40 & 32800 & 300 & 0.39 \\
50 & 25900 & 400 & 0.65 \\
60 & 9270 & 130 & 1.98 \\
67.8 & 12780 & 90 & 1.34 \\
73 & 16880 & 190 & 0.87 \\
75 & 10900 & 140 & 2.19 \\
78 & 16150 & 150 & 0.83 \\
82.9 & 13090 & 170 & 1.14 \\
90 & 12800 & 200 & 1.05 \\
100 & 11450 & 110 & 1.14 \\
\hline
\end{tabular}


$E, \mathrm{~J} \mathrm{~mol}^{-1}$

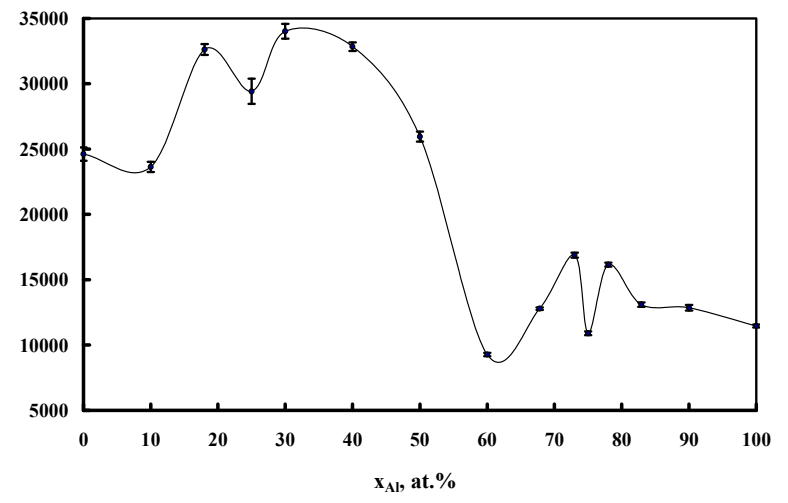

Fig. 5. The concentration dependence of activation energy of viscous flow of melts of $\mathrm{Cu}-\mathrm{Al}$ system. The limits are identified of the error of approximation of temperature dependences by the exponential function (3).

\subsection{Results of the densimetric experiments}

Temperature dependences of the density of Al-Cu melts containing $10,17.1$, and 23 at. $\% \mathrm{Cu}$ have been measured. The measurements were conducted at heating and subsequent cooling with the aim of finding signs of their irreversible transition from metastable microheterogeneous state into a thermodynamically stable state of a homogeneous solution. The results of the measurements are given in figure 6 .

$\rho, \mathrm{kg} \mathrm{m}^{-3}$

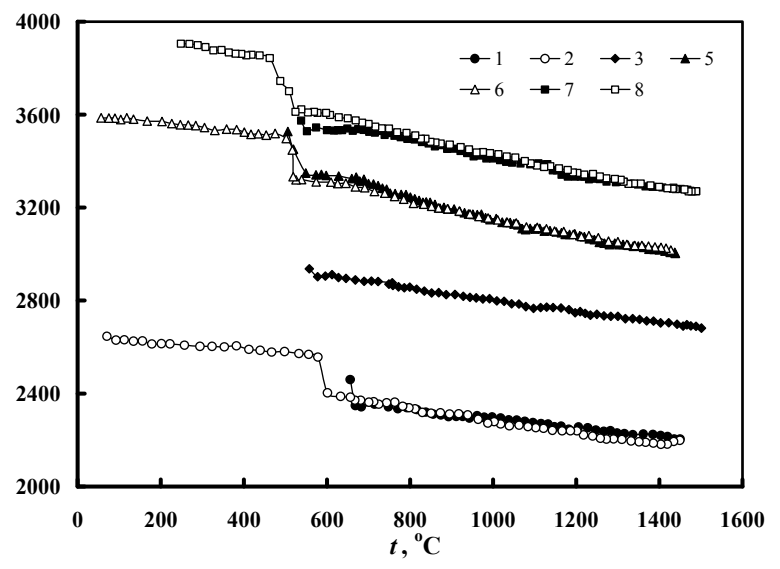

Fig. 6. Temperature dependences of the density of the investigated Al-Cu melts: (1) and (2) 0 at.\% $\mathrm{Cu}$, (3) 10, (5) and (6) 17, (7) and (8) 23 (for convenience of the reader, the curves are shifted upward by $200 \mathrm{~kg} \mathrm{~m}^{-3}$ ). Odd designations heating, even designations - cooling.

During their analysis one can see that the temperature dependences of density both in liquid and in solid states can be approximated by linear functions. At heating the temperature dependence of density in liquid state is different from the cooling curve at temperatures below $750^{\circ} \mathrm{C}$ for the eutectic melt containing 17 at.\% $\mathrm{Cu}$ and at the temperature below $800^{\circ} \mathrm{C}$ for the melt containing 23 at. $\% \mathrm{Cu}$, that is, we observe the phenomenon of density hysteresis. The branching of the heating and cooling curves definitely exceeds the measurement error, therefore, this effect is credible and requires further discussion. At closer examination of curves one can notice that both at heating and at cooling a certain stabilization of the values of density (almost a horizontal plateau) stretching for $70-100^{\circ} \mathrm{C}$ precedes the crystallization of the sample. This effect is not very pronounced, therefore, we do not discuss it before getting information about alloys with other concentrations of copper.

Since the temperature dependences of density are linear, we approximated the $\rho(T)$ curves by linear functions of the type:

$\rho=\rho_{\text {r o o m }}\left(1-a\left(T-T_{\text {room }}\right)\right)$,

for the liquid state and

$\rho=\rho_{\mathrm{m}}\left(1-a\left(T-T_{\mathrm{m}}\right)\right)$,

for the solid state. Here $\rho_{\text {room }}, \rho_{\mathrm{m}}$ are the densities of the samples at room temperature $T_{\text {room }}$ and melting temperature $T_{\mathrm{m}}$, correspondingly, and $a$ is the thermal coefficient of expansion.

It should be mentioned that in the solid state we approximate only the dependence received at cooling, since the heating curve corresponds to the initial sample that does not have a cylindrical shape yet.

The results of the approximation are given in Table 3.

Table 3. Parameters of the linear approximation of temperature dependences of the density of Al-Cu melt.

\begin{tabular}{|c|c|c|c|}
\hline $\begin{array}{c}x_{\mathrm{Cu}}, \\
\text { at.\% }\end{array}$ & Mode & $\begin{array}{c}\rho_{\mathrm{m}}\left(\rho_{\mathrm{r} \text { o m }}\right), \\
\mathrm{k} \mathrm{g} \mathrm{m}^{-3}\end{array}$ & $\begin{array}{c}a, \\
10^{-5} \mathrm{~K}^{-1}\end{array}$ \\
\hline \multirow{3}{*}{0} & Cooling (solid) & $(2541)$ & 5.3 \\
\cline { 2 - 4 } & Cooling (liquid) & 2275 & 9.4 \\
\cline { 2 - 4 } & Heating (liquid) & 2275 & 9.4 \\
\hline 10 & Heating (liquid) & 2799 & 8.5 \\
\hline \multirow{3}{*}{17.1} & Cooling (solid) & $(3480)$ & 5.3 \\
\cline { 2 - 4 } & Cooling (liquid) & 3210 & 11.1 \\
\cline { 2 - 4 } & Heating (liquid) & 3202 & 10.9 \\
\hline \multirow{3}{*}{23} & Cooling (solid) & $(3656)$ & 8.2 \\
\cline { 2 - 4 } & Cooling (liquid) & 3292 & 11.7 \\
\cline { 2 - 4 } & Heating (liquid) & 3265 & 11.1 \\
\hline
\end{tabular}

Using the received values of the parameters of the linear approximation of temperature dependences of density we calculated the values of density of the investigated $\mathrm{Al}-\mathrm{Cu}$ melts at fixed temperatures. The results are given in Table 4.

Using the values given there we built isotherms of the density of these melts which are given in figure 7 . Using the values of density at fixed temperatures we calculated the corresponding values of molar volume $V_{\text {mol }}$ which are given in Table 5 and built the isotherms of the molar volume given in figure 8 .

\section{Discussion}


One can identify among the nontrivial results of measurements of viscosity and density of copperaluminum melts the branching of temperature dependences obtained from heterogeneous charge materials, i.e., with the homogenization of melt referred to in the Introduction. This interpretation is favored by the absence of this effect in liquid copper melts and in samples of stoichiometric composition of $\mathrm{Cu}_{3} \mathrm{Al}$, which have a homogeneous crystal structure.

Table 4. The values of density of Al-Cu melts at fixed temperatures, $\mathrm{kg} \mathrm{m}^{-3}$.

\begin{tabular}{|c|c|c|c|c|}
\hline$x_{\mathrm{Cu}}$, at. $\%$ & 0 & 10 & 17.1 & 23 \\
\hline $700^{\circ} \mathrm{C}$ & 2351.5 & 2875.6 & 3266.9 & 3353.2 \\
$750^{\circ} \mathrm{C}$ & 2340.6 & 2863.4 & 3248.4 & 3333.3 \\
$800^{\circ} \mathrm{C}$ & 2329.8 & 2851.2 & 3230.0 & 3313.4 \\
$850^{\circ} \mathrm{C}$ & 2318.9 & 2839.1 & 3211.6 & 3293.5 \\
$900^{\circ} \mathrm{C}$ & 2308.1 & 2826.9 & 3193.1 & 3273.6 \\
$950^{\circ} \mathrm{C}$ & 2297.2 & 2814.7 & 3174.7 & 3253.6 \\
$1000^{\circ} \mathrm{C}$ & 2286.3 & 2802.5 & 3156.2 & 3233.7 \\
$1050^{\circ} \mathrm{C}$ & 2275.5 & 2790.3 & 3137.8 & 3213.8 \\
$1100^{\circ} \mathrm{C}$ & 2264.6 & 2778.2 & 3119.3 & 3193.9 \\
$1150^{\circ} \mathrm{C}$ & 2253.8 & 2766.0 & 3100.9 & 3174.0 \\
$1200^{\circ} \mathrm{C}$ & 2242.9 & 2753.8 & 3082.5 & 3154.1 \\
$1250^{\circ} \mathrm{C}$ & 2232.1 & 2741.6 & 3064.0 & 3134.2 \\
$1300^{\circ} \mathrm{C}$ & 2221.2 & 2729.4 & 3045.6 & 3114.3 \\
$1350^{\circ} \mathrm{C}$ & 2210.4 & 2717.3 & 3027.1 & 3094.4 \\
$1400^{\circ} \mathrm{C}$ & 2199.5 & 2705.1 & 3008.7 & 3074.5 \\
$1450^{\circ} \mathrm{C}$ & 2188.6 & 2692.9 & 2990.2 & 3054.6 \\
$1500^{\circ} \mathrm{C}$ & 2177.8 & 2680.7 & 2971.8 & 3034.7 \\
\hline
\end{tabular}

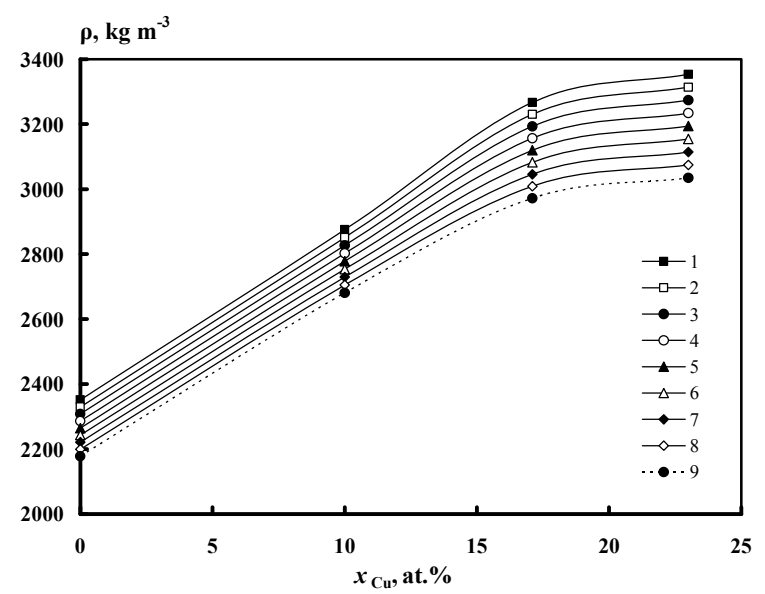

Fig. 7. The isotherms of the density of Al-Cu melts: (1) $700^{\circ} \mathrm{C}$, (2) 800 , (3) 900, (4) 1000, (5) 1100, (6) 1200, (7) 1300, (8) 1400, (9) 1500.

The shape of $v(t)$ curves in alloys containing 82.9 to 100 at.\% $\mathrm{Al}$ is very reminiscent of the respective dependences of liquid aluminum. Bazin et al. [9] associate this pattern of dependences with the structure transformation of aluminum melt from low-temperature structure of short-range order to high-temperature one. This hypothesis may be corroborated by the results of $\mathrm{X}$-ray analysis $[12,13]$ which revealed, at $790^{\circ} \mathrm{C}$, the shift of all maxima of scattering curve $I(Q)$ towards large angles $Q$, the disappearance of subsidiary maximum on the first peak, and the emergence of additional maximum in the region of high values of $Q$.
In our case, an anomaly under heating is observed in the vicinity of $950^{\circ} \mathrm{C}$; however, according to Bazin et al. [9], this difference between the transition temperatures may be associated with differences in purity of aluminum under investigation. Obviously, the inverse transition from high-temperature structure of shortrange order to low-temperature one occurs with significant supercooling; this causes the discrepancy between viscosity curves in a limited temperature region. Agreement between the $v(t)$ curves under heating and cooling in the vicinity of liquidus for samples containing up to 82.9 and 90 at.\% $\mathrm{Al}$ may imply either that superheating above $1100^{\circ} \mathrm{C}$ may be required for their irreversible homogenization or that the effect of structure transformation in the "aluminum" phase prevails over the effect of homogenization of microheterogeneous melt in the case of low content of the "copper" phase in this melt.

Table 5. The values of molar volume of Al-Cu melts at fixed temperatures, $10^{-5} \mathrm{~m}^{3} \mathrm{~mol}^{-1}$.

\begin{tabular}{|c|c|c|c|c|}
\hline$x_{\mathrm{Cu}}$, at. $\%$ & 0 & 10 & 17.1 & 23 \\
\hline $700^{\circ} \mathrm{C}$ & 1.15 & 1.07 & 1.02 & 1.06 \\
$750^{\circ} \mathrm{C}$ & 1.15 & 1.07 & 1.02 & 1.06 \\
$800^{\circ} \mathrm{C}$ & 1.16 & 1.07 & 1.03 & 1.07 \\
$850^{\circ} \mathrm{C}$ & 1.16 & 1.08 & 1.03 & 1.07 \\
$900^{\circ} \mathrm{C}$ & 1.17 & 1.08 & 1.04 & 1.08 \\
$950^{\circ} \mathrm{C}$ & 1.17 & 1.09 & 1.05 & 1.09 \\
$1000^{\circ} \mathrm{C}$ & 1.18 & 1.09 & 1.05 & 1.09 \\
$1050^{\circ} \mathrm{C}$ & 1.19 & 1.10 & 1.06 & 1.10 \\
$1100^{\circ} \mathrm{C}$ & 1.19 & 1.10 & 1.07 & 1.11 \\
$1150^{\circ} \mathrm{C}$ & 1.20 & 1.11 & 1.07 & 1.12 \\
$1200^{\circ} \mathrm{C}$ & 1.20 & 1.11 & 1.08 & 1.12 \\
$1250^{\circ} \mathrm{C}$ & 1.21 & 1.12 & 1.08 & 1.13 \\
$1300^{\circ} \mathrm{C}$ & 1.21 & 1.12 & 1.09 & 1.14 \\
$1350^{\circ} \mathrm{C}$ & 1.22 & 1.13 & 1.10 & 1.14 \\
$1400^{\circ} \mathrm{C}$ & 1.23 & 1.13 & 1.10 & 1.15 \\
$1450^{\circ} \mathrm{C}$ & 1.23 & 1.14 & 1.11 & 1.16 \\
$1500^{\circ} \mathrm{C}$ & 1.24 & 1.14 & 1.12 & 1.17 \\
\hline
\end{tabular}

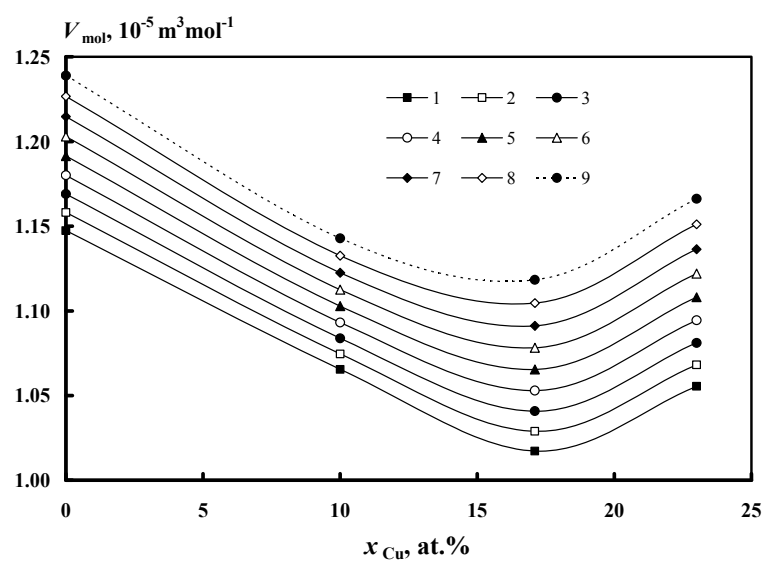

Fig. 8. The isotherms of the molar volume of $\mathrm{Al}-\mathrm{Cu}$ melts: (1) $700^{\circ} \mathrm{C}$, (2) 800 , (3) 900 , (4) 1000 , (5) 1100 , (6) 1200, (7) 1300, (8) 1400, (9) 1500.

It was already mentioned that an extremum was observed in $[10,11]$ on the viscosity isotherm in the vicinity of composition of $\mathrm{Cu}_{3} \mathrm{Al}$, which was interpreted 
by the authors as evidence that micro groupings of unlike atoms of this composition are retained in the liquid phase. We observed the viscosity maximum at 30 at. $\%$ Al, i.e., at a concentration close to $\gamma_{1}$ and $\gamma_{2}$-phases $\left(\mathrm{Cu}_{9} \mathrm{Al}_{4}\right)$, which enables one to refine the composition of these atomic microgroupings in the melt. More intriguing is the extremum in the vicinity of the stoichiometric composition of $\mathrm{CuAl}_{3}$, because no intermetallic compounds are present in the state diagram at this concentration. The only reasonable hypothesis in this case appears to be that of existence in the melt of atomic micro groupings of the foregoing composition, which exhibit a high thermal stability and serve the function of basic units of viscous flow.

We can see that our isotherms of molar volume $V_{\mathrm{mol}}(x)$ in the interval from 0 to 20 at.\% $\mathrm{Cu}$ deviate downwards from the additive dependence. This means that $\mathrm{Al}-\mathrm{Cu}$ alloys are formed with the decrease of atomic volume, i.e. with compression. Such behaviour is characteristic of systems with the dominating interaction of dissimilar components. Evidently, the energy of interaction between copper atoms and aluminum atoms in this range of compositions is considerably higher than the energy of interaction between similar atoms $\mathrm{Al}-\mathrm{Al}$ and $\mathrm{Cu}-\mathrm{Cu}$. Such behavior is natural for the $\mathrm{Al}-\mathrm{Cu}$ system, as there are a lot of compounds in its state diagram. The nontrivial result is the fact that there are no compounds in the investigated part of the composition, nevertheless, the negative deviations from additivity are very pronounced. These results are in good agreement with the above-mentioned maximum of viscosity in the vicinity of 25 at. $\% \mathrm{Cu}$.

\section{References}

1. I.G. Brodova, P.S. Popel, G.I. Eskin, Liquid Metal Processing: Applications to Aluminium Alloy Production (New York: Taylor and Francis, 2002)

2. I.G. Brodova, P.S. Popel, N.M. Barbin, N.A. Vatolin, Iskhodnye rasplavy kak osnova formirovaniya struktury $i$ svoistv alyuminievykh splavov (Starting Melts as the Basis for Forming the Structure and Properties of Aluminum Alloys) (Ekaterinburg: UrO RAN (Ural Div., Russ. Acad. Sci.), 2005)

3. V.M. Chursin, Nauchn. Tr. Mosk. Inst. Stali i Splavov, 123, 12 (1980)

4. S. Ganesan, R. Speiser, D.R. Poirier, Metall. Trans. B 18, 421 (1987)

5. E. Gebhardt, M. Becher, M. Doner, Aluminium, 31, 315 (1955)

6. A.M. Korol'kov, Izv. Akad. Nauk SSSR. Metall. i Toplivo, 3, 146 (1961)

7. V.M. Zamyatin, Ya.A. Nasyirov, N.I. Klassen et al., Zh. Fiz. Khim., 60 1, 243 (1986)

8. E.G. Shvidkovskii, Nekotorye voprosy vyazkosti ras-plavlennykh metallov (Some Problems Associated with the Viscosity of Molten Metals) (Moscow: GITTL, 1955)
9. Yu.A. Bazin, V.M.amyatin, Ya.A. Nasyirov, A.V. Emel'yanov, Izv. Vyssh. Uchebn. Zaved. Chern.Metall., 5, 28 (1985)

10. W.R.D. Jones, W.L. Bartlett, J. Inst. Metals, 83, 59 (1954)

11. K.I. Eretnov, A.P. Lyubimov, Izv. Vyssh. Uchebn. Zaved. Tsvetn. Metall., 1, 119 (1966)

12. N.A. Vatolin, E.A.Pastukhov, Difraktsionnye issledovaniya stroeniya vysokotemperaturnykh rasplavov (Diffraction Studies into the Structure of High-Temperature Melts) (Moscow: Nauka, 1977)

13. N.A. Vatolin, E.A. Pastukhov, V.N. Sermyagin, Dokl. Akad. Nauk SSSR, 222 3, 641 (1975) 